\title{
Gambling Subgroups among Korean Out-of-school Adolescents
}

\author{
Kyonghwa Kang ${ }^{1}$, Yi Kyung $\mathrm{Ha}^{2}$, Hwal Lan Bang ${ }^{3}$ \\ ${ }^{1}$ Assistant Professor, Department of Nursing, Chungwoon University, Hongseong; ${ }^{2}$ Assistant Professor, Department of Nursing, Dong-Eui University, Busan; \\ ${ }^{3}$ Assistant Professor, Department of Nursing, Andong National University, Andong, Korea
}

Purpose: The number of Korean adolescents engaging in gambling is increasing, especially among out-of-school adolescents. This study aimed to identify patterns of gambling activities and factors related to specific subgroups of out-of-school adolescent gambling activities. Methods: This descriptive study analyzed secondary data from the 2015 Korea Youth Gambling Problem Survey, including 1,200 out-of-school adolescents. Latent class analysis was conducted to identify patterns of gambling activities. The factors related to gambling subgroups were verified with multinomial logistic regression. Results: Three latent classes of gambling activities were identified: rarely gambling (RG), immediate gain gambling (IGG), and broad gambling (BG). These subgroups differed significantly in terms of gender, age at and type of first gambling experience, number and type of gambling activities, gambling frequency, time and money spent on gambling, problem gambling severity, and motivation for gambling. Compared to the RG subgroup, both the IGG and BG subgroups were strongly associated with an older age at the first gambling experience. Conclusion: Out-of-school adolescents who first gambled at an older age and who gambled mainly in order to gain money immediately were at risk of problem gambling. Developing strategies for early screening and referral to professionals is necessary to prevent gambling problems from worsening.

Key words: Adolescent; Gambling; Latent class analysis; Prevention

\section{Corresponding author Hwal Lan Bang \\ https://orcid.org/0000-0003-1115-6484}

Department of Nursing, Andong National University,

1375 Gyeongdong-ro, Andong 36729, Korea

TEL +82-54-820-5686 FAX +82-54-820-6730

E-MAIL luvlucie@anu.ac.kr

Received Jun 7, 2020 Revised Jun 19, 2020 Accepted Jun 20, 2020 (a) This is an Open Access article distributed under the terms of the Creative Commons Attribution NonCommercial License (http://creativecommons.org/licenses/by-nc/4.0/) which permits unrestricted noncommercial use, distribution, and reproduction in any medium, provided the original work is properly cited.

\section{INTRODUCTION}

\section{Need for Study}

The definition of out-of-school adolescents varies greatly depending on the perspective of various organizations. In the past, this concept was limited to adolescents who had left school. However, in recent years, it has included not only adolescents who have switched from traditional learning to a variety of different educational frameworks, such as alternative schools, lifelong education facilities, and vocational training institutions, but also those who have left regular schools for various reasons, such as those who live in shelters or are on probation, and those who do not attend school because they suffer from diseases [1]. There are 263 million out-of-school children and adolescents globally, corresponding to nearly one-fifth of this age group [2]. As of 2015, it was estimated that $6.3 \%$ of school-age adolescents in Korea did not attend school for various reasons [3].

Out-of-school adolescents lack social support from school and friends, which has been cited as a protective factor against risk behaviors such as drinking, smoking, and adolescent problem gambling [4,5]. Gambling is the act of wagering stakes, mostly cash or something of value, on an event with an un- 
certain outcome [6], and has traditionally been recognized as an adult recreational activity. Out-of-school adolescents are reported to have easier access to games [3], and the boundaries between internet games and gambling have become blurred in recent years. Increased access to gambling among adolescents has stimulated hopes and expectations that they could win money, without recognizing the harmfulness of gambling; this dynamic heightens the risk of problem gambling and negative phenomena such as engaging in illegal gambling [7].

Nevertheless, little is known about the gambling behavior of out-of-school adolescents and their risk for gambling addiction. Most studies on out-of-school adolescents have been limited to identifying variables affecting risk behaviors such as drinking, smoking, or drug abuse and reasons for academic suspension. Thus, a need exists to identify the characteristics of the gambling activities of out-of-school adolescents. However, determining the presence of problem gambling by simply scoring the level of problem gambling using a screening tool can result in stigmatization [8]. Instead, using a subject-centered (person-centered) approach such as latent class analysis (LCA) can help to identify subgroups that require interventions for problem gambling [9].

LCA is a model-based method that categorizes relationships between variables, including unobserved potential variables, until the optimal number of mutually exclusive groups is identified based on post-probability [10]. The individuals within a subgroup are assumed to be homogeneous, making it easier to identify the characteristics of the target group. Once the latent classes, corresponding to subgroups of gambling behaviors, are identified, preventive interventions can be customized according to the characteristics of each subgroup [11].

The study aimed to characterize the subgroups of gambling behaviors of out-of-school adolescents and to generate evidence to serve as a basis for developing specific intervention programs for subgroups of gambling behaviors among outof-school adolescents.

\section{METHODS}

\section{Study Design}

This descriptive study analyzed secondary data from the 2015 Korea Youth Gambling Problem Survey [12] to identify the characteristics of the subgroups of gambling activities among out-of-school adolescents.

\section{Subjects}

The study included 1,200 male and female out-of-school adolescents who participated in the 2015 Korea Youth Gambling Problem Survey conducted by the Korean Center on Gambling Problems [12].

\section{Measures}

\section{1) Types of gambling}

To analyze the patterns of gambling activities, the probability values of 11 gambling activities were calculated based on participants' responses (yes or no). The five types of offline gambling were as follows: cards or hwatu (Korean cards), claw or prize draws, sports betting, wagering (betting other than sports betting), and lotteries. The six types of online gambling were as follows: online cards using Netmarble (www.netmarble.net), Hangame (www.hangame.com), etc.; online wagering; online lottery purchases; online sports betting using bet-man; online illegal sports betting, and internet casinos.

\section{2) Gambling-related characteristics}

To explore gambling-related characteristics, age at first gambling experience, type of first gambling and gambling within last three months, gambling companion, frequency of gambling, amount of money spent and lost on gambling, largest amount of money won by betting, and reasons for gambling were analyzed.

\section{3) Gambling problem severity}

The Gambling Problem Severity Scale (GPSS) from the Canadian Adolescent Gambling Index (CAGI) [13] was used to assess the severity of participants' gambling problem in the last 3 months. The scores are classified into three severity categories: green light $(0 \sim 1$, no problem gambling); yellow light (2 5, low-to-moderate severity); red light (over 6, high severity). Cronbach's $\alpha$ was .83 .90, the sensitivity was .97 , and the specificity was .93 when the tool was developed [13]. Cronbach's $\alpha$ in this study was 87 .

\section{Data Collection}

The Youth Gambling Problem Survey has been conducted once every 3 years since 2015 among school and out-of-school adolescents in Korea, with the aim of collecting and using basic data to identify gambling behaviors and to develop gambling prevention projects [12]. The current study utilized data from the 2015 survey. Out-of-school youth support centers, juvenile shelters, alternative schools, probation centers, and juvenile reformatories were selected for data collection because there was no sampling frame for probability sampling. The data were collected by allocating the target sample size 
for each institution according to the number of teenagers registered at the institution. The Institutional Review Board (IRB) of Andong National University approved the IRB exemption for analyzing the secondary data (No. 1040191-201902-HR001-01).

\section{Data Analysis}

The frequency and distribution of the variables of the participants were calculated, the sociodemographic characteristics and gambling-related characteristics of the latent classes were analyzed by the $x^{2}$ test and the Fisher exact test, and one-way analysis of variation, and post-hoc testing was conducted using the Scheffé test. The factors related to gambling subtypes were verified with multinomial logistic regression by maximum likelihood estimation. LCA determines the optimal number of subgroups by considering statistical criteria such as the appropriate statistical fit indices and the accuracy of the classification $[10,14]$. Fit indices, such as the Akaike information criterion (AIC) and the Bayesian information criterion (BIC) were estimated, and the latent classes with the lowest AIC and BIC values were considered to be the optimal model. The Lo-Mendell-Rubin adjusted likelihood ratio test (LMR-LRT) was used to compare the models (k-group models). A non-significant value (i.e., $p>.050$ ) for this index indicates that a model with $\mathrm{k}-1$ classes should be accepted. The number of potential classes was determined by checking the distribution and the p-value for the maximum likelihood between the k-1 and k-group models while increasing the number of potential classes. When comparing two competing model-based cluster solutions, lower entropy means that there is less variability within each cluster and, therefore, that the model is more homogeneous. M-plus version 8.3 was used for LCA and SPSS version 23.0 for Windows (IBM Corp., Armonk, NY, USA) was used for other statistical analyses.

\section{RESULTS}

\section{General Characteristics}

The average age of the survey respondents was $16.7 \pm 1.3$ years. The average age at quitting school was $15.4 \pm 1.7$ years. Among the respondents, $62.7 \%$ had experienced gambling at least once in their lifetime, and $40.4 \%$ had gambled within the last 3 months (Table 1 ).

\section{Characteristics of Subgroups of Gambling Activities}

Using LCA, the subgroups of gambling activities of out-ofschool adolescents were identified. The researchers fitted two-
Table 1. Characteristics of the Participants

$(N=1,200)$

\begin{tabular}{|c|c|}
\hline Variables & $\mathrm{n}(\%)$ or $\mathrm{M} \pm \mathrm{SD}$ \\
\hline $\begin{array}{l}\text { Gender } \\
\text { Male } \\
\text { Female }\end{array}$ & $\begin{array}{l}766(63.8) \\
434(36.2)\end{array}$ \\
\hline Age (year) & $16.7 \pm 1.3$ \\
\hline Age at quitting school (year) & $15.4 \pm 1.7$ \\
\hline Age at first gambling experience (year) & $14.0 \pm 2.8$ \\
\hline $\begin{array}{l}\text { Type of institution } \\
\text { Youth support center } \\
\text { Juvenile shelter/alternative school } \\
\text { Probation center } \\
\text { Juvenile reformatory }\end{array}$ & $\begin{array}{l}537(44.8) \\
123(10.2) \\
281(23.4) \\
259(21.6)\end{array}$ \\
\hline $\begin{array}{l}\text { Lifetime gambling experience } \\
\text { Yes } \\
\text { No }\end{array}$ & $\begin{array}{l}752(62.7) \\
448(37.3)\end{array}$ \\
\hline $\begin{array}{l}\text { Gambling experience within } 3 \text { months } \\
\text { Yes } \\
\text { No }\end{array}$ & $\begin{array}{l}485(40.4) \\
715(59.6)\end{array}$ \\
\hline $\begin{array}{l}\text { GPSS/CAGI score } \\
\quad \leq 1 \text { (green light, no problem) } \\
2 \sim 5 \text { (yellow light, low to moderate) } \\
\geq 6 \text { (red light, high severity) }\end{array}$ & $\begin{array}{l}961(80.1) \\
129(10.8) \\
110(9.1)\end{array}$ \\
\hline $\begin{array}{l}\text { Frequency of gambling within } 3 \text { months } \\
\leq 1 \text { time per week } \\
2 \sim 6 \text { times per week } \\
\text { Everyday }\end{array}$ & $\begin{array}{c}362(74.7) \\
103(21.2) \\
20(4.1)\end{array}$ \\
\hline $\begin{array}{l}\text { Motivation for gambling* }(\mathrm{n}=473) \\
\text { To win money } \\
\text { For excitement } \\
\text { Because of curiosity } \\
\text { To get away from negative feelings } \\
\text { To hang out with friends }\end{array}$ & $\begin{array}{c}161(34.1) \\
203(42.9) \\
86(18.2) \\
12(2.5) \\
11(2.3)\end{array}$ \\
\hline
\end{tabular}

*Missing data were not included; GPSS=Gambling Problem Severity Scale; CAGI=Canadian Adolescent Gambling Index.

to four-class models that were evaluated using the appropriate statistical fit indices, such as AIC and BIC. A three-class model showed lower values of the AIC and BIC and an entropy lower than 1. LMR-LRT was used to verify the model, and a non-significant value was found for the four-class model. The best-fitting model was the three-class model $(p<.001)$ (Table 2).

The three subgroups from LCA were defined and named by the 11 distinct types of gambling activities in which individuals participated over the last 3 months, as shown in Figure 1. Subgroup 1 was the largest group, accounting for $69.5 \%$ of the sample. Subgroup 1 was named as 'rarely gambling (RG)' because it included individuals who participated in gambling activities rarely, except for prize draws. Sub- 
Table 2. Model Fit Indices of Latent Class Analysis of Gambling Behaviors of Out-of-school Adolescents

$(N=1,200)$

\begin{tabular}{|c|c|c|c|c|c|}
\hline Model & AIC & BIC & Entropy & LMR-LRT & $p^{*}$ \\
\hline 1 class & $9,692.76$ & $9,748.75$ & - & - & \\
\hline 2 classes & $7,025.72$ & $7,142.79$ & 0.93 & $2,659.78$ & $<.001$ \\
\hline 3 classes $^{\dagger}$ & $6,694.65$ & $6,872.80$ & 0.88 & 350.95 & $<.001$ \\
\hline 4 classes & $6,633.02$ & $6,872.25$ & 0.87 & 84.63 & .104 \\
\hline
\end{tabular}

${ }^{*} p$-value for the $\mathrm{k}$ versus $\mathrm{k}-1$ class solution; ${ }^{\dagger}$ Selected model; $\mathrm{AIC}=$ Akaike information criterion; $\mathrm{BIC}=$ Bayesian information criterion; LMR-LRT=Lo-Mendel-Rubin adjusted likelihood ratio test.

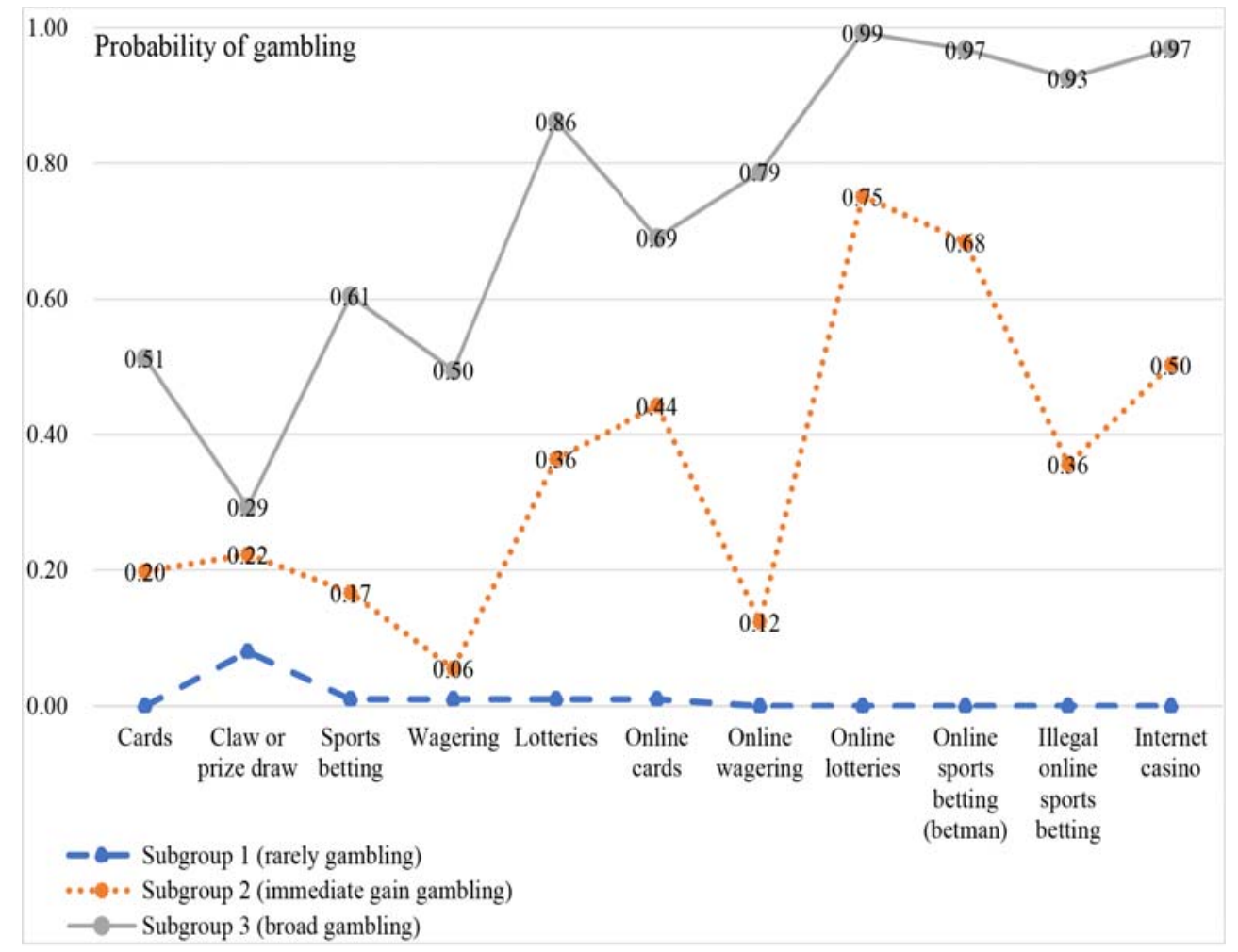

Figure 1. Latent class analysis of gambling activities among Korean out-of-school adolescents.

group 2 included adolescents who engaged mainly in online lotteries and online sports betting. Subgroup 2 was named as 'immediate gain gambling (IGG)' because these individuals engaged in gambling activities in which they immediately knew whether they won or lost. The adolescents in subgroup 3 were 'broad gambling (BG)' adolescents who engaged in almost every gambling activity, except for claw or prize draws. The subgroups differed significantly in terms of gender, age, type of institution, age at quitting school, age at first gambling experience, type of first gambling, number and type of gambling behaviors, gambling frequency, time and amount spent on gambling, problem gambling severity, and motivation for gambling (Table 3).

\section{Factors Related to Gambling Subgroups}

The explanatory power of the final model was statistically significant, with a Nagelkerke $\mathrm{R}^{2}$ of .464 (-2 log likelihood $501.29, p<.001)$. As the age at first gambling experience increased by 1 unit, participants were significantly more likely to belong to the IGG subgroup, by 1.49 times ( $95 \%$ confidence interval $[\mathrm{CI}]=1.20 \sim 1.85, p<.001$ ), or the BG subgroup, by 1.13 times $(95 \% \mathrm{CI}=1.00 \sim 1.28, p=.043)$. Participants in the IGG subgroup were more likely to have high CAGI scores (odds ratio $[\mathrm{OR}]=1.24,95 \% \mathrm{CI}=1.08 \sim 1.42$ ) (Table 4). 
Table 3. Subgroup-specific Characteristics

$(N=1,200)$

\begin{tabular}{|c|c|c|c|c|c|}
\hline \multirow[t]{2}{*}{ Item } & $\begin{array}{c}\text { Subgroup } 1 \\
\text { (rarely gambling) }\end{array}$ & $\begin{array}{c}\text { Subgroup } 2 \\
\text { (immediate gain gambling) } \\
\end{array}$ & $\begin{array}{c}\text { Subgroup } 3 \\
\text { (broad gambling) }\end{array}$ & \multirow[t]{2}{*}{$x^{2}$ or $\mathrm{F}$} & \multirow[t]{2}{*}{$p$} \\
\hline & $\mathrm{n}(\%)$ or $\mathrm{M} \pm \mathrm{SD}$ & $\mathrm{n}(\%)$ or $\mathrm{M} \pm \mathrm{SD}$ & $\mathrm{n}(\%)$ or $\mathrm{M} \pm \mathrm{SD}$ & & \\
\hline Gender & & & & 31.99 & $<.001$ \\
\hline Male & $500(60.0)$ & $108(85.7)$ & $158(65.8)$ & & \\
\hline Female & $334(40.0)$ & $18(14.3)$ & $82(34.2)$ & & \\
\hline Age (year) & $16.64 \pm 1.28^{\mathrm{a}}$ & $16.96 \pm 0.94^{\mathrm{b}}$ & $16.83 \pm 1.10^{\mathrm{ab}}$ & 4.29 & .014 \\
\hline $\begin{array}{l}\text { Type of institution } \\
\text { Youth support center } \\
\text { Juvenile shelter/alternative school } \\
\text { Probation center } \\
\text { Juvenile reformatory }\end{array}$ & $\begin{array}{r}405(48.6) \\
87(10.4) \\
204(24.5) \\
138(16.5)\end{array}$ & $\begin{array}{l}31(24.6) \\
6(4.8) \\
19(15.1) \\
70(55.5)\end{array}$ & $\begin{array}{r}101(42.1) \\
30(12.5) \\
58(24.2) \\
51(21.2)\end{array}$ & 100.81 & $<.001$ \\
\hline Age at quitting school (year) & $15.31 \pm 1.59^{\mathrm{a}}$ & $15.66 \pm 1.44^{\mathrm{c}}$ & $15.53 \pm 1.49^{\mathrm{b}}$ & 3.16 & .043 \\
\hline Age at first gambling experience (year) & $13.34 \pm 3.03^{\mathrm{a}}$ & $15.32 \pm 1.62^{\mathrm{c}}$ & $14.22 \pm 2.70^{\mathrm{b}}$ & 26.57 & $<.001$ \\
\hline $\begin{array}{l}\text { Type of first gambling } \\
\text { Offline } \\
\text { Online } \\
\text { Illegal online }\end{array}$ & $\begin{array}{l}336(87.0) \\
35(9.1) \\
15(3.9)\end{array}$ & $\begin{array}{l}60(47.6) \\
44(34.9) \\
22(17.5)\end{array}$ & $\begin{array}{c}180(75.0) \\
50(20.8) \\
10(4.2)\end{array}$ & 89.64 & $<.001$ \\
\hline $\begin{array}{l}\text { Type of gambling within } 3 \text { months } \\
\text { Offline } \\
\text { Online } \\
\text { Illegal online }\end{array}$ & $\begin{array}{r}100(84.0) \\
14(11.8) \\
5(4.2)\end{array}$ & $\begin{array}{l}36(28.6) \\
51(40.5) \\
39(30.9)\end{array}$ & $\begin{array}{r}170(70.8) \\
58(24.2) \\
12(5.0)\end{array}$ & 11.07 & $<.001$ \\
\hline $\begin{array}{l}\text { Frequency of gambling within } 3 \text { months } \\
\leq 1 \text { time per week } \\
2 \sim 6 \text { times per week } \\
\text { Everyday }\end{array}$ & $\begin{array}{r}107(90.7) \\
10(8.5) \\
1(0.8)\end{array}$ & $\begin{array}{l}59(47.2) \\
55(44.0) \\
11(8.8)\end{array}$ & $\begin{array}{c}194(80.9) \\
38(15.8) \\
8(3.3)\end{array}$ & $70.63^{\dagger}$ & $<.001$ \\
\hline $\begin{array}{l}\text { Gambling companion } \\
\text { Alone } \\
\text { Family or acquaintance } \\
\text { Adults and strangers }\end{array}$ & $\begin{array}{l}36(30.3) \\
77(64.7) \\
6(5.0)\end{array}$ & $\begin{array}{l}26(20.8) \\
97(77.6) \\
2(1.6)\end{array}$ & $\begin{array}{r}47(19.6) \\
180(75.0) \\
13(5.4)\end{array}$ & 8.79 & .067 \\
\hline Number of gambling sessions experienced & $0.31 \pm 0.46^{\mathrm{a}}$ & $7.50 \pm 1.86^{\mathrm{c}}$ & $3.01 \pm 1.10^{\mathrm{b}}$ & $2,358.53$ & $<.001$ \\
\hline Time spent on gambling (minute) & $87.77 \pm 143.09^{\mathrm{a}}$ & $139.58 \pm 150.21^{\mathrm{b}}$ & $82.83 \pm 99.98^{\mathrm{a}}$ & 13.80 & $<.001$ \\
\hline Money spent on gambling (KRW) & $103,768.91 \pm 478,537.18^{\mathrm{a}}$ & $1,105,651.59 \pm 1,784,192.18^{\mathrm{b}}$ & $251,282.47 \pm 823,375.51^{\mathrm{a}}$ & 31.87 & $<.001$ \\
\hline Money lost on gambling (KRW) & $63,128.15 \pm 377,696.43^{\mathrm{a}}$ & $744,117.07 \pm 1,446,931.01^{\mathrm{b}}$ & $145,770.13 \pm 519,621.27^{\mathrm{a}}$ & 25.76 & $<.001$ \\
\hline Money won from gambling (KRW) & $228,264.53 \pm 808,308.87^{\mathrm{a}}$ & $1,147,921.29 \pm 1,497,429.83^{\mathrm{b}}$ & $215,205.45 \pm 445,155.14^{\mathrm{a}}$ & 41.84 & $<.001$ \\
\hline $\begin{array}{l}\text { GPSS/CAGI score } \\
\quad \leq 1 \text { (green, no problem) } \\
2 \sim 5 \text { (yellow, low to moderate severity) } \\
\geq 6 \text { (red, high severity) }\end{array}$ & $\begin{array}{c}1.21 \pm 2.34^{\mathrm{a}} \\
805(96.5) \\
21(2.5) \\
8(1.0)\end{array}$ & $\begin{array}{l}6.16 \pm 5.48^{\mathrm{c}} \\
30(23.8) \\
35(27.8) \\
61(48.4)\end{array}$ & $\begin{array}{r}2.63 \pm 3.45^{\mathrm{b}} \\
126(52.5) \\
73(30.4) \\
41(17.1)\end{array}$ & $\begin{array}{r}54.93 \\
563.09\end{array}$ & $\begin{array}{l}<.001 \\
<.001\end{array}$ \\
\hline $\begin{array}{l}\text { Motivation for gambling } \\
\text { To win money } \\
\text { For excitement } \\
\text { Because of curiosity } \\
\text { To get away from negative feelings } \\
\text { To hang out with friends }\end{array}$ & $\begin{array}{l}19(16.2) \\
56(47.9) \\
33(28.2) \\
6(5.1) \\
3(2.6)\end{array}$ & $\begin{array}{c}70(57.9) \\
36(29.8) \\
13(10.7) \\
1(0.8) \\
1(0.8)\end{array}$ & $\begin{aligned} 72 & (30.6) \\
111 & (47.2) \\
40 & (17.0) \\
5 & (2.2) \\
7 & (3.0)\end{aligned}$ & 50.50 & $<.001$ \\
\hline Total $^{*}$ & $834(69.5)$ & $126(10.5)$ & $240(20.0)$ & & \\
\hline
\end{tabular}

${ }^{*}$ Missing data were not included; ${ }^{\dagger}$ Fisher exact test; ${ }^{\mathrm{a}, \mathrm{b}, \mathrm{c}}$ Scheffé test (mean values with another letter indicate significant differences); KRW=Korean Won; GPSS=Gambling Problem Severity Scale; CAGI=Canadian Adolescent Gambling Index. 
Table 4. Multinomial Logistic Regression Analysis for Gambling Subgroup-related Variables

$(N=1,200)$

\begin{tabular}{|c|c|c|c|c|c|c|}
\hline \multirow{3}{*}{ Variables } & \multicolumn{6}{|c|}{ Model (reference: rarely gambling subgroup) } \\
\hline & \multicolumn{3}{|c|}{ Immediate gain gambling subgroup } & \multicolumn{3}{|c|}{ Broad gambling subgroup } \\
\hline & OR & $95 \%$ CI & $p$ & OR & $95 \% \mathrm{CI}$ & $p$ \\
\hline GPSS/CAGI score & 1.24 & $1.08 \sim 1.42$ & .002 & 1.12 & $0.99 \sim 1.27$ & .082 \\
\hline Age at first gambling experience (year) & 1.49 & $1.20 \sim 1.85$ & $<.001$ & 1.13 & $1.00 \sim 1.28$ & .043 \\
\hline $\begin{array}{l}\text { Most frequent type of gambling } \\
\text { Offline } \\
\text { Online } \\
\text { Illegal online }\end{array}$ & $\begin{array}{l}0.23 \\
0.89\end{array}$ & $\begin{array}{l}0.06 \sim 0.84 \\
0.21 \sim 3.73\end{array}$ & $\begin{array}{l}.026 \\
.875\end{array}$ & $\begin{array}{l}1.83 \\
3.67\end{array}$ & $\begin{array}{l}0.47 \sim 7.19 \\
0.83 \sim 16.27\end{array}$ & $\begin{array}{l}.385 \\
.087\end{array}$ \\
\hline $\begin{array}{l}\text { Frequency of gambling within } 3 \\
\text { months }\end{array}$ & 1.39 & $0.99 \sim 1.96$ & .055 & 1.03 & $0.78 \sim 1.36$ & .835 \\
\hline Time spent on gambling (minute) & 1.00 & $0.99 \sim 1.00$ & .488 & 1.00 & $1.00 \sim 1.00$ & .707 \\
\hline Money spent on gambling (KRW) & 1.00 & $1.00 \sim 1.00$ & .939 & 1.00 & $1.00 \sim 1.00$ & .575 \\
\hline Money lost on gambling (KRW) & 1.00 & $0.90 \sim 1.00$ & .879 & 0.87 & $0.81 \sim 0.94$ & .824 \\
\hline Money won from gambling (KRW) & 1.00 & $1.00 \sim 1.00$ & .203 & 1.00 & $1.00 \sim 1.00$ & .172 \\
\hline $\begin{array}{l}\text { Type of institution } \\
\text { Youth support center } \\
\text { Juvenile shelter/alternative school } \\
\text { Probation center } \\
\text { Juvenile reformatory }\end{array}$ & $\begin{array}{l}0.60 \\
1.96 \\
0.35\end{array}$ & $\begin{array}{l}0.21 \sim 1.74 \\
0.28 \sim 13.58 \\
0.11 \sim 1.10\end{array}$ & $\begin{array}{l}.346 \\
.498 \\
.425\end{array}$ & $\begin{array}{l}0.79 \\
3.85 \\
0.68\end{array}$ & $\begin{array}{l}0.31 \sim 1.97 \\
0.73 \sim 20.30 \\
0.27 \sim 1.75\end{array}$ & $\begin{array}{l}.605 \\
.112 \\
.425\end{array}$ \\
\hline $\begin{array}{l}-2 \log \text { likelihood } \\
x^{2}(\mathrm{df}) \\
\text { Nagelkerke } \mathrm{R}^{2}\end{array}$ & & & $\begin{array}{r}501.29 \\
26.00 \\
.464\end{array}$ & & & \\
\hline
\end{tabular}

CAGI=Canadian Adolescent Gambling Index; CI=Confidence interval; GPSS=Gambling Problem Severity Scale; KRW=Korean Won; OR=Odds ratio.

\section{DISCUSSION}

This study investigated the characteristics of gambling subgroups in order to provide a basis for preventing gambling problems among out-of-school adolescents. The lifetime gambling experience rate of out-of-school adolescents was $62.7 \%$, which is higher than the rate of $42.1 \%$ among school students in Korea [13], and similar to the rate of $61.4 \%$ among students in the United States [15]. The gambling prevalence of adolescents reported in studies conducted after 2010 was $46.5 \%$ in Hong Kong, 50.8\% in Australia, and 70.1\% in Denmark [16-18]. However, the samples were mostly among school students, suggesting the need to provide an overview of the gambling activities of out-of-school adolescents.

Gambling activities of out-of-school adolescents were classified into three subgroups (RG, IGG, and BG), whereas prior studies classified their subjects into $4 \sim 8$ subgroups $[8,14,19$, 20]. This result is consistent with the findings of a prior study on early adulthood gambling, which delineated three subgroups of social gamblers, problem gamblers, and pathological gamblers [21]. However, it contrasts with the findings of other LCA studies among adolescents that yielded four to eight subgroups, indicating a need to understand the specific gambling characteristics of out-of-school youth [19,20,22].

Subgroup 1 (RG) was used as a reference to compare other groups because $69.5 \%$ of the adolescents did not not gamble often and were in this group.

The IGG subgroup was associated with a high probability of online lotteries, online sports betting, and internet casinos compared to the RG subgroup. Adolescents in the IGG subgroup had the highest scores for the severity of problem gambling. There is a concern that they may transition into serious problem gambling in adulthood. When adolescents gamble on the internet, their gambling behavior remains hidden, such that it is not easy to recognize the progression of addiction until the problem becomes more serious [23]. Individuals in the IGG subgroup gambled mainly to win money, engaging in gambling activities that are played alone without interacting with others, such as online lotteries or sports betting. Compared to individuals in the RG subgroup, those in the IGG subgroup engaged in about 25 times the number of gambling games, spent 1.5 times the number of minutes gambling 
and spent about 10 times the money. Consistent with previous studies, those who gambled more and spent more money had problematic patterns of behavior $[20,22]$. Adolescents tend to be impulsive and to pursue stronger stimuli [14]. They engage in various gambling activities, increasing the amount of betting, especially on gambling games that they think can reward them with money in a short period of time [22]. Therefore, it is necessary to provide intensive management programs for recognizing problem gambling and regulating the gambling behavior of adolescents.

Individuals in the BG subgroup engaged in almost every gambling activity except claw or prize draws. The number of gambling games played by adolescents in the BG subgroup was about 9 times more than those played by individuals in the RG subgroup, and the amount spent on gambling was twice as high. BG adolescents gambled for excitement or fun rather than to win money, while IGG adolescents gambled mainly to win money. Adolescents become immersed in gambling activities that begin with fun-seeking and curiosity about their gambling peers because adolescents who lack a culture have no choice but to create a subculture [23]. It is necessary to educate them with factual information about the risks of gambling so that their betting for fun does not cross the boundaries of 'play.'

A predictive variable of the BG and IGG subgroups was age at first gambling experience. As an individual gets older, low-risk gambling can develop into online and/or illegal casinos and adult gambling addiction $[15,24]$. This finding is supported by a report of Korean Center on Gambling Problems that higher school grades were associated with increased levels and risk of problem gambling [25]. Effective prevention policies are required for out-of-school adolescents who are at higher risk of being exposed to gambling problems than inschool teenagers.

This study is significant in that, firstly, latent subgroups and the characteristics of gambling among out-of-school adolescents in Korea were identified. Secondly, this study suggested that gambling activities experienced at a later age are related to problem gambling. To the best of our knowledge, this study is the first report on the gambling activities of outof-school adolescents that included adolescents in institutions where data collection is usually limited. The results should be interpreted carefully because of the limitations inherent in convenience sampling. Further studies are needed to develop programs to prevent problem gambling.

\section{CONCLUSION}

Gambling activities among out-of-school adolescents were classified into three latent subgroups: RG, IGG, and BG. The adolescents in the IGG subgroup scored high in the severity of problem gambling and they spent a considerable amount of time and money on gambling. Out-of-school adolescents who first gambled at an older age and who gambled mainly to win money were at risk of problem gambling. Developing strategies for early screening and referral to professionals is necessary to manage their gambling problems. Adolescents, especially those who are out-of-school, need to be provided with various alternative activities and opportunities to participate in play culture other than gambling. In the future, it is necessary to develop tailored interventions that reflect the characteristics of these subgroups of out-of-school adolescents and to investigate factors that affect their gambling behavior.

\section{Conflict of interest}

No existing or potential conflict of interest relevant to this article was reported.

\section{REFERENCES}

1. Oh BD, Kim KH. The statistical estimation of out-of-school youth population for the youth welfare policy in Korea. Journal of Adolescent Welfare. 2013;15(4):31-54.

2. UNESCO Institute for Statistics (UIS). One in five children, adolescents and youth is out of school [Internet]. Montreal: United Nations Educational Scientific and Cultural Organization Institute for Statistics; 2018 [cited 2019 August 20]. Available from: http://uis.unesco.org/sites/default/files/documents/fs48-onefive-children-adolescents-youth-out-school-2018-en.pdf

3. Ministry of Gender Equality and Family; National Youth Policy Institute. 2015 Out-of-school adolescents survey [Internet]. Seoul: Ministry of Gender Equality and Family; 2015 [cited 2019 March 22]. Available from:

http://www.mogef.go.kr/kor/skin/doc.html?fn=33775.pdf\&rs= /rsfiles/202007/

4. Davidoff AJ, Kenny GM. Uninsured Americans with chronic health conditions: Key findings from the national health interview survey [Internet]. Baltimore: Urban Institute and University of Maryland; 2003 [cited 2019 August 20]. Available from: http://webarchive.urban.org/UploadedPDF/411161_uninsured _americans.pdf

5. Canale N, Vieno A, Lenzi M, Griffiths MD, Borraccino A, Lazzeri $\mathrm{G}$, et al. Income inequality and adolescent gambling severity: Findings from a large-scale Italian representative survey. Frontiers in Psychology. 2017;8:1-12. https://doi.org/10.3389/fpsyg.2017.01318

6. US National Research Council. Pathological gambling: A critical review. 1st ed. Washington, DC: National Academy Press; 1999. p. 16. https://doi.org/10.17226/6329 
7. Hume M, Mort GS. Fun, friend, or foe: Youth perceptions and definitions of online gambling. Social Marketing Quarterly. 2011;17 (1):109-133. https:// doi.org/10.1080/15245004.2010.546939

8. Kang K, Kim H, Park AR, Kim HY, Lee K. Latent class analysis of gambling activities among Korean adolescents. Journal of Korean Academy of Nursing. 2018;48(2):232-240.

https://doi.org/10.4040/jkan.2018.48.2.232

9. Lanza ST, Rhoades BL. Latent class analysis: An alternative perspective on subgroup analysis in prevention and treatment. Prevention Science. 2013;14(2):157-168.

https://doi.org/10.1007/s11121-011-0201-1

10. Collins LM, Lanza ST. Latent class and latent transition analysis: With applications in the social, behavioral, and health sciences. 1st ed. Hoboken NJ: John Wiley and Sons; 2010. p. 8-18.

11. Goodman LA. Exploratory latent structure analysis using both identifiable and unidentifiable models. Biometrika. 1974;61(2):215-231. https://doi.org/10.2307/2334349

12. The National Gambling Control Commission; Korea Center on Gambling Problems. Survey on 2015 youth gambling problem. Survey Report. Seoul: Korea Center on Gambling Problems; 2015 December. Report No.: Research-15-06.

13. Tremblay J, Stinchfield R, Wiebe J, Wynne H. Canadian adolescent gambling inventory (CAGI) phase III final report [Internet]. Calgary: Alberta Gaming Research Institute; 2010 [cited 2019 Oct 13]. Available from: https://prism.ucalgary.ca/handle/1880/48158

14. Kong G, Tsai J, Krishnan-Sarin S, Cavallo DA, Hoff RA, Steinberg $\mathrm{MA}$, et al. A latent class analysis of pathological-gambling criteria among high school students: Associations with gambling, risk and health/functioning characteristics. Journal of Addiction Medicine. 2014;8(6):421-430.

https://doi.org/10.1097/ADM.0000000000000074

15. Welte JW, Barnes GM, Tidwell MCO, Hoffman JH. The association of form of gambling with problem gambling among American youth. Psychology of Addictive Behaviors. 2009;23(1):105-112. https://doi.org/10.1037/a0013536

16. Hsu SM, Lam LMC, Wong ILK. A Hong Kong school-based survey: Impacts of parental gambling on adolescent gambling behavior and mental health status. Asian Journal of Gambling Issues and Public Health. 2014;4:3.

https://doi.org/10.1186/2195-3007-4-3
17. Delfabbro P, King D. Adolescent gambling in metropolitan Darwin: Prevalence, correlates and social influences. Gambling Research. 2011;23(1):3-23.

18. Kristiansen S, Jensen SM. Prevalence of gambling problems among adolescents in the Nordic countries: An overview of national gambling surveys 1997-2009. International Journal of Social Welfare. 2011;20(1):75-86.

https://doi.org/10.1111/j.1468-2397.2009.00701.x

19. De Luigi N, Gibertoni D, Randon E, Scorcu AE. Patterns of gambling activities and gambling problems among Italian high school students: Results from a latent class analysis. Journal of Gambling Studies. 2018;34(2):339-359. https://doi.org/10.1007/s10899-017-9694-2

20. Studer J, Baggio S, Mohler-Kuo M, Simon O, Daeppen JB, Gmel G. Latent class analysis of gambling activities in a sample of young Swiss men: Association with gambling problems, substance use outcomes, personality traits and coping strategies. Journal of Gambling Studies. 2016;32(2):421-440.

https://doi.org/10.1007/s10899-015-9547-9

21. Chamberlain SR, Stochl J, Redden SA, Odlaug BL, Grant JE. Latent class analysis of gambling subtypes and impulsive/compulsive associations: Time to rethink diagnostic boundaries for gambling disorder? Addictive Behaviors. 2017;72:79-85.

https://doi.org/10.1016/j.addbeh.2017.03.020

22. Boldero JM, Bell RC, Moore SM. Do gambling activity patterns predict gambling problems? A latent class analysis of gambling forms among Australian youth. International Gambling Studies. 2010;10(2):151-163. https://doi.org/10.1080/14459795.2010.501808

23. Ha MJ, Park SY. A study about youth gambling addiction process: Based on verbal statements that adults experienced gambling addiction during adolescence. Mental Health and Social Work. 2015; 43(3):220-249.

24. Mazar A, Williams RJ, Stanek EJ, Zorn M, Volberg RA. The importance of friends and family to recreational gambling, at-risk gambling, and problem gambling. BMC Public Health. 2018;18(1): 1-14. https://doi.org/10.1186/s12889-018-5988-2

25. The National Gambling Control Commission; Korea Center on Gambling Problems. Survey on 2018 youth gambling problem. Survey Report. Seoul: Korea Center on Gambling Problems; 2018 December. Report No.: Preventive promotion-18-19. 